\title{
Antiviral selection in the management of acute retinal necrosis
}

This article was published in the following Dove Press journal:

Clinical Ophthalmology

5 January 2010

Number of times this article has been viewed

\author{
Patrick MK Tam' \\ Claire Y Hooper ${ }^{2}$ \\ Susan Lightman ${ }^{2}$ \\ 'Department of Ophthalmology \\ and Visual Sciences, The Chinese \\ University of Hong Kong, Prince of \\ Wales Hospital, N.T., Hong Kong, \\ People's Republic of China; ${ }^{2}$ Institute \\ of Ophthalmology, Moorfields Eye \\ Hospital, London, UK
}

\begin{abstract}
There is no consensus on the optimal antiviral regimen in the management of acute retinal necrosis, a disease caused by herpetic viruses with devastating consequences for the eye. The current gold standard is based on retrospective case series. Because the incidence of disease is low, few well-designed, randomized trials have evaluated treatment dosage and duration. Newer oral antiviral agents are emerging as alternatives to high-dose intravenous acyclovir, avoiding the need for inpatient intravenous treatment. Drug resistance is uncommon but may also be difficult to identify. Antiviral drugs have few side effects, but special attention needs to be paid to patients who have underlying renal disease, are pregnant or are immunocompromised.
\end{abstract}

Keywords: acute retinal necrosis, acyclovir, herpes, retinitis

\section{Introduction}

Acute retinal necrosis (ARN) is an uncommon, but potentially blinding, uveitic syndrome characterized by progressive peripheral necrotizing retinitis. ${ }^{1}$ The American Uveitis Society diagnostic criteria (1994) defines ARN as a necrotizing retinitis with one or more foci that exhibits circumferential spread with evidence of occlusive vasculopathy, an inflammatory reaction in the anterior chamber and vitreous that is independent of the extent of retinal necrosis, age, gender and the immune status of the patient. ${ }^{2}$ It was first described by Urayama et al in $1971,{ }^{3}$ but it was more than a decade later before a herpetic etiology was discovered and antiviral therapy became the mainstay of treatment. ${ }^{4}$ Today, ARN is recognized as being predominantly caused by varicella zoster virus (VZV) and herpes simplex virus types 1 and 2 (HSV-1, HSV-2), with some studies implicating cytomegalovirus (CMV) and Epstein-Barr virus (EBV). ${ }^{4-9}$ While the diagnosis of ARN is usually straightforward, much controversy surrounds its management. Debate continues on the benefit or otherwise of aspirin, corticosteroids, barrier laser and prophylactic vitrectomy. ${ }^{10-12}$ More fundamentally, there is a lack of consensus on the best antiviral regime; the "conventional regimen" derived more than 20 years ago was still used as gold standard in recent studies that looked at different aspects of ARN management such as the effect of prophylactic vitrectomy and intraoperative antiviral lavage ${ }^{11,12}$ This review focuses on the current understanding of acyclovir in the management of ARN. For completeness, we have also included other antiviral agents that have been reported in the literature to be effective.

\section{Historical perspective}

The clinical triad of acute panuveitis, occlusive retinal arteritis and peripheral retinal necrosis was first described in Japanese literature as Kirisawa's uveitis in $1971 .^{3}$ 
Later, Martenet in 1976 and Young and Bird in 1978 coined the term 'acute retinal necrosis'. ${ }^{13,14}$ Natural history studies demonstrated a very poor prognosis in the pre-acyclovir era. A review, which integrated 52 cases of ARN reported in 11 series, found that $75 \%$ of affected eyes progressed to retinal detachment. Only $22 \%$ of these eyes achieved anatomic reattachment and only $28 \%$ had a final visual acuity of 20/200 or better. ${ }^{10}$

In 1982 Culbertson, Blumenkranz and associates studied the histopathology and electron microscope findings of an eye enucleated from a patient with acute retinal necrosis. ${ }^{4}$ Histology revealed eosinophilic intranuclear inclusions in retinal cells and electron microscopy demonstrated a herpes group virus in all layers of affected retina. They confirmed these findings, identifying VZV as the cause, in two supporting cases published in $1986^{5}$ and in the same year reported their initial experience with intravenous acyclovir in the treatment of ARN. Thirteen eyes of 12 patients were treated with intravenous acyclovir $10 \mathrm{mg} / \mathrm{kg} 3$ times daily for an average of 10.9 days. Initial and complete regression of retinal lesions was noted on average 3.9 days and 32.5 days respectively after treatment initiation. No eye developed new retinal lesions or progressive optic nerve involvement 48 hours or more after treatment initiation. No systemic or ocular side effects from treatment were noted. ${ }^{15}$

Crapotta et al subsequently reported treating 13 eyes of 12 patients with the same intravenous acyclovir regime for 8 to 21 days followed by oral acyclovir (400 to $800 \mathrm{mg}$ 5 times daily) for at least 2 weeks after intravenous acyclovir treatment was discontinued. In 11 of the 12 patients there was complete resolution of active lesions within 21 days of initiation of antiviral therapy. Two patients developed reactivation after resolution 2 and 5 weeks after cessation of oral acyclovir which resolved after recommencement of acyclovir. Final visual acuity was 20/40 or better in 6 eyes and 20/400 or better in 12 eyes. No patient developed bilateral disease over a median follow up of 9.5 months. ${ }^{16}$ In 1991, Palay et al reviewed the course of 54 patients who had unilateral ARN at initial examination. Thirty-one patients were treated with intravenous acyclovir, whereas 23 were not treated with acyclovir. Two years after initial onset, $25 \%$ of the group treated with acyclovir developed ARN in the fellow eye compared with $65 \%$ of the group not treated with acyclovir. ${ }^{17}$

From these early papers derives the standard treatment for ARN detailed in current ophthalmic texts. The recommended regime is intravenous acyclovir $10 \mathrm{mg} / \mathrm{kg}$ every 8 hours (or $1500 \mathrm{mg} / \mathrm{m}^{2}$ ) per day for 5 to 10 days, followed by oral acyclovir 400 to $800 \mathrm{mg} 5$ times daily for an additional 6 to 12 weeks. Six weeks was decided as the minimum duration of subsequent oral therapy because second eye involvement typically occurs within the first six weeks. However, although this is considered the traditional treatment, no prospective studies have investigated the optimal duration of intravenous treatment, timing of switching to oral therapy, or ideal total treatment duration.

Recently, Kawaguchi et al have recommended commencing intravenous acyclovir at a dose of $15 \mathrm{mg} / \mathrm{kg}$ three times daily, provided the patient has no renal impairment. ${ }^{18}$ They argued that ocular lesions in patients with ARN due to VZV often tend to be more severe and progress more rapidly than those associated with HSV. Therefore they initiate acyclovir treatment at a higher dose until the causative virus is identified by polymerase chain reaction (PCR) on ocular fluid. If the PCR results confirm HSV as the causative virus, the dosage is reduced to $10 \mathrm{mg} / \mathrm{kg} 3$ times daily. Intravenous therapy is followed by 6 weeks of oral antiviral therapy. They question the efficacy of using oral antiviral agents alone for the treatment of severe cases of ARN. Others have advocated supplementing intravenous acyclovir therapy with intravitreal injections of ganciclovir or foscarnet for severe cases of ARN. ${ }^{19-21}$ Ganciclovir and foscarnet injections and ganciclovir implants have been shown to be effective in treating progressive outer retinal necrosis (PORN), ${ }^{22}$ a more fulminant form of retinal necrosis due to VZV or HSV which occurs in immunocompromised patients such as AIDS, ${ }^{23,24}$ organ transplantation, ${ }^{25}$ leukemia ${ }^{26}$ and non-Hodgkin lymphoma. ${ }^{27}$

Conversely, there are an increasing number of ophthalmic centers that are switching to oral therapy alone. Proponents reason that the current standard treatment of ARN was based on anecdotal evidence and predated the availability of oral valacyclovir and famciclovir which have superior plasma bioavailability compared with oral acyclovir. In 1997, Figueroa et al reported a case of ARN unresponsive to intravenous acyclovir that was successfully treated with oral famciclovir. ${ }^{28}$ In 2002, Aslanides et al described three cases of ARN who were treated with oral valacyclovir $1 \mathrm{~g} 3$ times daily for 3 weeks ( 2 patients) or 3 months ( 1 patient). No new lesions appeared 3 to 4 days after initiation of treatment and complete resolution was achieved by 2 months. Final visual acuities were 20/25, 20/30 and 20/40 and there was no recurrence of disease or fellow eye involvement over a 6- to 12 -month follow-up period. ${ }^{29}$ Emerson et al described similar success with 2 patients treated with oral valacyclovir (1 g 3 times daily) and 2 patients treated oral famciclovir 
(500 mg 3 times daily) although they emphasized that all 4 cases were relatively indolent. ${ }^{30}$

The largest consecutive case series of patients with ARN treated solely with oral antiviral therapy was reported by Aizman et al in 2007. ${ }^{31}$ Ten eyes of 8 patients were treated with either oral valacyclovir $1 \mathrm{~g} 3$ times daily (4 eyes) or oral famciclovir $500 \mathrm{mg} 3$ times daily (6 eyes) for a mean of 12 weeks and then the dose was tapered over a mean of 13 weeks. One patient with bilateral ARN received a single intravitreal injection of foscarnet $2.4 \mathrm{mg} / 0.1 \mathrm{~mL}$ in the more severely involved eye. All 10 eyes had complete resolution of retinitis. Initial regression of retinitis was observed on average 6.3 days after initiation of treatment and required an average of 17 days for complete resolution. This compares favorably with the results of intravenous acyclovir treatment reported by Blumenkranz et al who noted initial regression 3.9 days into treatment and complete resolution 32.5 days after commencing treatment. ${ }^{15}$ Final visual acuity was improved in 6 eyes, stable in 2 eyes and worse in 2 eyes. One patient, on a maintenance dose of oral acyclovir $400 \mathrm{mg}$ twice daily for impaired immunity, developed a recurrence 11 months after the initial episode that resolved with recommencement of famciclovir. None of the 4 patients with initially unilateral disease developed fellow eye involvement.

In summary, due to the rarity of the disease and a lack of prospective clinical trials, there is no current consensus on the optimal treatment of ARN. Many authors still employ the traditional regime of intravenous acyclovir $10 \mathrm{mg} / \mathrm{kg}$ 3 times daily for 5 to 10 days followed by oral acyclovir 400 to $800 \mathrm{mg} 5$ times daily for at least 6 weeks. However, oral antiviral therapy alone is being increasingly adopted as an alternative. This remainder of this review will explore the mode of action, antiviral activity, pharmacokinetics and tolerability of the various antiviral agents to determine evidence for the various regimes.

\section{Acyclovir}

\section{Pharmacology: mechanism of action}

The antiviral effect of acyclovir was first described in 1977 and was the result of a systematic search for a drug capable of exploiting the fact that viral-infected cells are induced by the virus to produce thymidine kinase. ${ }^{32}$ The affinity of acyclovir for virus-specific thymidine kinase is approximately 200 times greater than its affinity for cellular thymidine kinase. Hence, intracellular acyclovir is rapidly and preferentially phosphorylated by virus-specific thymidine kinase to form acyclovir monophosphate, creating a concentration gradient favoring uptake by infected cells compared with non-infected cells. Host cellular enzymes then complete the phosphorylation to acyclovir triphosphate, the active form of the drug. Acyclovir triphosphate inhibits viral replication by acting as a competitive substrate for viral DNA polymerase, and its subsequent incorporation into the viral DNA chain results in obligate chain termination. Replication of HSV is inhibited at concentrations up to 3000 -fold lower than those required to inhibit mammalian cellular functions. Acyclovir is therefore highly specific for herpes-infected cells and, as it selectively converted to its active form in virus-infected cells, it is non-toxic to uninfected cells.

\section{Antiviral activity}

Although acyclovir displays inhibitory activity against all herpesviruses in vitro, great variations in sensitivity exist among individual subtypes. The dose of acyclovir required to reduce HSV-1 viral plaques by $50 \%$ in tissue culture (Inhibitory concentration $50 \%, \mathrm{IC}_{50}$ ), is less than $0.1 \mu \mathrm{M}$ for most and $2.0 \mu \mathrm{M}$ in rare, resistant strains. ${ }^{33}$ Varicella-zoster virus and $\mathrm{EBV}$ have intermediate $\mathrm{IC}_{50}$ values that range from 1.3 to $20.6 \mu \mathrm{M}$ (mean 3 to $4 \mu \mathrm{M}$ ) and 0.3 to $25.0 \mu \mathrm{M}$, $, 34,35$ respectively, while $\mathrm{IC}_{50}$ values for $\mathrm{CMV}$, the least sensitive of the herpesvirus group, have been reported to be as high as $200 \mu \mathrm{M} .^{35}$

\section{Pharmacokinetics}

Gastrointestinal absorption of acyclovir is slow, highly variable and incomplete with an oral bioavailability of $15 \%$ to $30 \%{ }^{36}$ Peak plasma concentrations $\left(\mathrm{C}_{\max }\right)$ are achieved 1.5 to 2.5 hours after oral administration and a short plasma half-life of 3 hours necessitates frequent ( 5 times per day) dosing. Whereas, plasma concentrations of 10 to $20 \mu \mathrm{g} / \mathrm{mL}$ can be achieved with intravenous acyclovir administration of 5 to $10 \mathrm{mg} / \mathrm{kg}$, regular oral doses of 200 to $800 \mathrm{mg}$ only yield concentrations of 0.6 to $1.6 \mu \mathrm{g} / \mathrm{mL}$. Approximately $15 \%$ of acyclovir is protein-bound. It achieves widespread tissue distribution, resulting in CSF levels $50 \%$ of that of plasma. A small fraction of acyclovir is metabolized by the liver, and its major metabolite accounts for only about $14 \%$ of an oral dose. The primary route of elimination of acyclovir is through the kidneys with $62 \%$ to $91 \%$ of acyclovir being excreted unchanged in the urine via both tubular secretion and glomerular filtration..$^{37,38}$

\section{Intraocular penetration of acyclovir}

Few studies looked specifically into the intravitreal penetration of acyclovir. Early studies only focused on the 
inhibitory concentrations for HSV-1 and HSV-2 in the aqueous, ${ }^{39,40}$ and hence their conclusions may not be extrapolated when we now realize ARN can be caused by viruses that have a higher $\mathrm{IC}_{50}$. One report has shown when given intravenously at $13 \mathrm{mg} / \mathrm{kg} 3$ times daily, intravitreal acyclovir concentrations of $17.9 \mu \mathrm{M}$ may be achieved. ${ }^{41}$ This is therapeutic for most strains of ARN-related viruses. In a study by Hung et al mean concentration in the aqueous humor after 5 doses of $400 \mathrm{mg}$ oral acyclovir 24 hours before elective cataract surgery was found to be $3.26 \mu \mathrm{M}$, a level he concluded as therapeutic for HSV-1. ${ }^{42}$ From the limited data available, one may conclude that higher intraocular levels of acyclovir can be achieved when given intravenously than orally, but neither treatment provide complete coverage for all known strains of viruses that are able to cause ARN. This may translate into the treatment-resistant cases and the evolution for combined antiviral treatment necessary in subsequent case reports.

\section{Viral resistance}

Despite the widespread use of acyclovir for three decades, the incidence of acyclovir-resistant HSV strains among immunocompetent persons has remained low, ranging from 0 to $0.6 \%{ }^{43-45}$ Resistance in immunocompromised patients in general is also uncommon with a prevalence of approximately $5 \%$. However, prevalence of HSV resistance in allogeneic bone marrow transplant patients has been reported to be as high as $30 \%{ }^{43-45}$ Resistance to acyclovir is associated with mutations on either viral thymidine kinase or DNA polymerase. ${ }^{46}$ In $95 \%$ of cases, acyclovir resistance is due to a mutation in the thymidine kinase gene as this enzyme is not essential for viral replication. Strains resistant to acyclovir are virtually always cross-resistant to other thymidine kinasedependent drugs such as penciclovir and famciclovir. These strains will be sensitive to foscarnet or cidofovir as these drugs inhibit viral DNA polymerase but they do not depend on thymidine kinase. ${ }^{47}$

\section{Valacyclovir}

\section{Pharmacology: mode of action}

\section{and antiviral activity}

Valacyclovir is the oral prodrug of acyclovir and has the same mode of action as acyclovir.

\section{Antiviral activity}

Valacyclovir is the oral prodrug of acyclovir and has the same antiviral activity as acyclovir.

\section{Pharmacokinetics}

Valacyclovir, the L-valyl ester of acyclovir, creates a substrate for active transport mechanisms in the human intestine. After absorption, valacyclovir undergoes rapid and virtually complete first pass metabolism in the intestine and liver to form acyclovir and the essential amino acid L-valine. ${ }^{48}$ This process is cytochrome P450 independent. The distribution, intracellular kinetics, metabolism and excretion of acyclovir once it enters the systemic circulation are identical whether it is administered as oral valacyclovir or oral or intravenous acyclovir.

The increased uptake and rapid hydrolysis of valacyclovir to acyclovir results in significantly greater systemic levels of acyclovir following oral valacyclovir ingestion compared with oral acyclovir ingestion. The mean bioavailability of acyclovir following a single $1 \mathrm{~g}$ dose of valacyclovir in healthy adult volunteers is $54.2 \% .{ }^{49} \mathrm{~A}$ similar bioavailability of acyclovir after valacyclovir of $45 \%$ to $48 \%$ was found in children. ${ }^{50}$ Single- and multiple-dose studies have demonstrated 3- to 5-fold increases in bioavailability of valacyclovir relative to oral acyclovir.

Administration of valacyclovir $250 \mathrm{mg} 4$ times daily results in acyclovir $\mathrm{C}_{\text {max }}$ and area under the concentration-time curve (AUC) values comparable to oral acyclovir $800 \mathrm{mg}$ 5 times daily. ${ }^{51}$ Daily acyclovir AUC values for valacyclovir at a dose of $1000 \mathrm{mg} 3$ times daily are similar to those obtained with intravenous acyclovir $5 \mathrm{mg} / \mathrm{kg}$ administered 3 times daily. Valacyclovir $2000 \mathrm{mg} 4$ times daily produces a daily AUC of $109 \mu \mathrm{g} \cdot \mathrm{h}^{-1} \mathrm{~mL}^{-1}$ which was identical to that achieved by intravenous acyclovir $10 \mathrm{mg} / \mathrm{kg}$ three times daily (AUC of $107 \mu \mathrm{g} \cdot \mathrm{h} \mathrm{h}^{-1} \mathrm{~mL}^{-1}$ ). ${ }^{52}$

\section{Intraocular penetration of valacyclovir}

In a study by Huynh et al the intravitreal concentrations of acyclovir in 10 uninflamed eyes of 10 subjects before elective pars plana vitrectomy after oral valacyclovir 1 gram three times daily was measured. A mean vitreous acyclovir concentration of $1.03 \mu \mathrm{g} / \mathrm{mL}$ and a vitreous-to-serum concentration ratio of 0.24 , ie, $25 \%$ of serum levels was found. ${ }^{53}$ Although the dose used in this study ( $1 \mathrm{~g} 3$ times daily) was proven effective in other case reports, ${ }^{30,31}$ vitreous acyclovir concentration was lower than a similar report that measured CSF acyclovir concentrations. ${ }^{54}$ The authors attributed this to the timing of sampling that might have led to an underestimation of the true peak concentration, and has suggested that the levels may be higher in ARN where there is a breach of the blood retinal barrier. More data are needed to elucidate the peak intravitreal levels following valacyclovir administration. 


\section{Other anti-viral drugs used \\ in management of ARN \\ Famciclovir}

Pharmacology: mode of action

Famciclovir is the oral prodrug of penciclovir. ${ }^{55}$ Like acyclovir, penciclovir is preferentially phosphorylated by virus-specific thymidine kinase to form penciclovir monophosphate. Host cellular enzymes then complete the phosphorylation to penciclovir triphosphate, the active form of the drug, which acts as a competitive substrate for viral DNA polymerase. Incorporation of penciclovir triphosphate into the viral DNA chain does not prevent additional bases from being added but renders the process inefficient and replication eventually ceases, a process known as conditional chain termination. The affinity of viral thymidine kinase for penciclovir is 100 -fold greater than that for acyclovir but the penciclovir triphosphate form is less effective than acyclovir triphosphate as an inhibiter of HSV DNA polymerase.

\section{Antiviral activity}

The $\mathrm{IC}_{50}$ values obtained for penciclovir (administered orally as the prodrug famciclovir) have been shown to be similar to those achieved with acyclovir (administered orally as the prodrug valacyclovir). An addition, it was shown famciclovir is able to reduce viral load at the ganglia level in mice, thereby reducing recurrence. The underlying mechanism for this effect is unknown. ${ }^{56,57}$

\section{Pharmacokinetics}

Famciclovir is rapidly and efficiently converted, via hydrolysis in the intestinal wall and oxidation in the liver, to penciclovir and acetic acid. The mean bioavailability of penciclovir following a single dose of famciclovir is $77 \%$ and peak serum concentrations are achieved within one hour. ${ }^{55}$ Penciclovir is only $20 \%$ protein bound and it achieves widespread tissue distribution. No significant metabolism occurs and approximately $60 \%$ is excreted unchanged by the kidneys. Its elimination half-life is 2 hours in healthy adult volunteers but prolonged intracellular half-life has been demonstrated in cells infected with VZV (9 to 14 hours), HSV-1 (10 hours) and HSV-2 (20 hours). ${ }^{58}$ Patients with hepatic insufficiency have $44 \%$ reduction in penciclovir mean plasma concentration compared to controls. Chong et al found a mean intravitreal penciclovir concentration of $1.21 \mu \mathrm{g} / \mathrm{mL}$ following 4 oral doses of famciclovir $500 \mathrm{mg}$. They concluded this is therapeutic for nonresistant restrains of HSV-1, HSV-2 and VZV (with $\mathrm{IC}_{50}$ of 0.04 to $0.06 \mu \mathrm{g} / \mathrm{mL}, 0.05$ to $2.1 \mu \mathrm{g} / \mathrm{mL}$ and 0.1 to $5.0 \mu \mathrm{g} / \mathrm{mL}$, respectively. ${ }^{59}$

\section{Valganciclovir}

\section{Pharmacology: mode of action}

Valganciclovir is the oral prodrug of ganciclovir and has the same mode of action as ganciclovir.

\section{Antiviral activity}

The efficacy of valganciclovir against CMV retinitis was proven in a multicenter trial. ${ }^{60}$ However, evidence for its use in acute retinal necrosis is scant. Savant et al described a case of VZV ARN in an immunocompetent woman who was successfully treated with valganciclovir. She was given valganciclovir $900 \mathrm{mg}$ twice daily induction for 3 weeks followed by once daily maintenance for 2 weeks. Oral acyclovir $400 \mathrm{mg}$ three times daily was continued for 3 months. ${ }^{61} \mathrm{In}$ another report, Cottet et al treated a case of HSV-2 ARN with intravenous acyclovir $10 \mathrm{mg} / \mathrm{kg} 3$ times daily for 4 weeks, oral valganciclovir $450 \mathrm{mg}$ twice daily for 2 weeks and a single intravitreal injection of ganciclovir $2000 \mu \mathrm{g}$. Oral acyclovir was continued for 3 months. The patient had a final vision of 1.0 bilaterally and undetectable viral DNA in aqueous at month $10 .{ }^{62}$

\section{Pharmacokinetics}

Valganciclovir is the L-valyl ester prodrug of ganciclovir with enhanced bioavailability. It is hydrolyzed in the intestinal tissues and hepatocytes to produce ganciclovir. ${ }^{63}$ After phosphorylation, the substrate of ganciclovir competitively inhibits deoxyguanosine triphosphate binding to DNA polymerase. This results in inhibition of viral DNA synthesis.

The bioavailability from valganciclovir is increased 10 -fold compared to oral ganciclovir ( $60 \%$ with food) ${ }^{64}$ An oral dose of $900 \mathrm{mg}$ achieves ganciclovir AUC similar to that with $5 \mathrm{mg} / \mathrm{kg}$ intravenous ganciclovir dosing. The elimination half-life of ganciclovir is 4.08 hours. This can be prolonged in patients with renal impairment. It is excreted in urine in forms of ganciclovir. ${ }^{64}$

\section{Safety and tolerability of antivirals in the management of acute retinal necrosis}

The specificity of acyclovir for virally infected cells and its selective conversion to the active form within virally infected cells results in favorable clinical safety and tolerability profiles. Renal impairment is the most common side effect and is related to its renal excretion and poor water solubility. ${ }^{65} \mathrm{It}$ can be in the form of intraluminal crystal precipitation ${ }^{66}$ or interstitial nephritis. ${ }^{67}$ Rapid intravenous bolus administration increases the risk although oral acyclovir can also cause 
acute renal failure in the setting of severe volume depletion and excessive oral dosage. ${ }^{68}$

The incidence of renal impairment associated with acyclovir has been reported to range from $12 \%$ to $48 \%{ }^{65,68}$ It is usually asymptomatic, but some patients may complain of nausea or vomiting and flank or abdominal pain. Urinalysis reveals hematuria and pyuria. Renal function usually recovers after drug cessation and volume resuscitation. Hemodialysis may be indicated when renal failure is severe. A reduction of acyclovir dose is essential in patients with underlying renal insufficiency and calculation of the appropriate acyclovir dose based on the estimated glomerular filtration rate will significantly reduce the risk of acute renal failure. ${ }^{70}$

Neurotoxicity occurs less frequently. Patients on continuous ambulatory peritoneal dialysis are at particular risk because it is not effective in the removal of plasma acyclovir. ${ }^{71}$ Clinical manifestations can sometimes mimic central nervous system involvement by herpesvirus and include lethargy, delirium, agitation, seizures, hallucinations and coma. Hemodialysis may sometimes be indicated.

\section{Pregnancy}

Experience has been gained in the use of acyclovir and valacyclovir during pregnancy for potentially severe conditions such disseminated HSV, varicella pneumonia, and severe primary genital herpes. The International Acyclovir Pregnancy Registry has monitored the birth outcome of more than 1200 women exposed to oral or intravenous acyclovir during pregnancy. In its latest report, the observed birth defect rate was $3.2 \%$ (95\% confidence interval, $2.0 \%$ to $5.0 \%){ }^{72}$ This is comparable to that of the general population. The authors concluded that acyclovir and valacyclovir exposure during pregnancy does not increase the rate of birth defects. Acyclovir and valacyclovir both belong to Pregnancy Drug Category B, meaning there is no clear evidence of risk in humans although there are no controlled studies to document safety.

\section{Immunocompromised}

Although usually a disease of immunocompetent persons, ARN can also occur in immunocompromised individuals. Aside from an increased prevalence of HSV resistance, ${ }^{43}$ no specific issues have been identified regarding acyclovir treatment in this population. Of note is the well-known association of herpetic encephalitis with ARN. In a retrospective report involving 52 patients with ARN, Vandercam et al identified 7 who had preceding herpetic encephalitis. The immunocompromised patients all had bilateral disease caused by VZV.
The authors concluded that herpetic encephalitis is a risk factor for ARN, and treatment may improve the outcome at least for the contralateral eye. ${ }^{73}$ The standard treatment for herpetic encephalitis is intravenous acyclovir $10 \mathrm{mg} / \mathrm{kg} 3$ times daily for at least 10 days. $^{74}$ Shorter duration of treatment is associated with occasional relapse with acyclovir-sensitive HSV. ${ }^{75}$ There is insufficient evidence to support valacyclovir as an equally effective agent to date.

Three randomized, controlled trials (RCTs) and one open-label study demonstrated the long-term safety of oral valacyclovir for suppression of recurrent genital HSV infection. A total of 3050 patients (1062 immunocompromised) were enrolled in the studies and 2206 received valacyclovir 250 to $1000 \mathrm{mg}$ /day for up to one year. ${ }^{76}$ Pooled together, the incidence of adverse events were $32 \%$ and $31 \%$ for valacyclovir and acyclovir respectively, this compares to $24 \%$ in the placebo group. The most frequent of them were headache, infectious illnesses (influenza, rhinitis, sinusitis), and nausea. These were regarded likely to be concurrent illnesses rather than a genuine adverse event, and given the potential consequences of ARN, the risks will probably be offset by its benefits. There seems to be no apparent relationship between total daily exposure to valacyclovir and the frequency or severity of adverse events. Nor was the long term use of valacyclovir associated with disturbances in hematological or biochemical profiles. ${ }^{76}$ Serious adverse events in immunocompetent patients that were believed to be attributed to the drug occurred in 3 valacyclovir recipients (leucopenia, hepatitis and headache) and 2 acyclovir recipients (myasthenia and suicidal ideation). Manifestations resembling thrombotic microangiopathy have been reported in clinical trials evaluating high doses of valacyclovir $(8000 \mathrm{mg} /$ day $)$ administered for prolonged periods (months to years) for prophylaxis of CMV infection and disease, particularly in persons with HIV infection. There were no reports of thrombotic microangiopathy among the 3050 subjects evaluating valacyclovir for suppression of genital herpes. The implication is occurrence of thrombotic microangiopathy is restricted to severely immunosuppressed subjects receiving high doses of valacyclovir. ${ }^{77}$

In both the single- and multiple-dose studies carried out in healthy volunteers, the safety profile of valacyclovir was excellent. Adverse experiences considered associated with study medication included headaches and gastrointestinal complaints. In a study that evaluated that the pharmacokinetics of multiple-dose valacyclovir in a group of 65- to 83-year-old volunteers, Wang et al found higher $\mathrm{C}_{\max }$ and mean AUC values when compared to younger subjects; 
these differences were attributed to the reduced creatinine clearance in the geriatric population. Valacyclovir was well tolerated in this population, with no serious adverse events reported. ${ }^{51}$

Hoglund and associates postulated that the lower peak plasma concentrations associated with oral therapy may reduce the risk of renal adverse events compared with intravenous acyclovir administration. ${ }^{78}$

In a large study of patients taking valacyclovir $1 \mathrm{~g} 3$ times daily, headache (17\%) and nausea $(14 \%)$ were the most common complaints. Another study of 60 healthy human volunteers taking valacyclovir $2 \mathrm{~g} 4$ times daily demonstrated no serious adverse events, with subjects reporting headaches and gastrointestinal disturbances. ${ }^{79}$ The authors suggested that in comparison to intravenous ACV, lower peak plasma acyclovir concentrations resulting from administration of oral valacyclovir may minimize the risk of renal adverse effects while providing similar clinical efficacy. ${ }^{52}$

The limit of the administration of high dosage valacyclovir is mostly the renal and central nervous system (CNS) toxicity of the drug that can be avoided by adequate hydration and dose adjustment to creatinine clearance. These high valacyclovir dosages have been indeed well tolerated when prescribed to kidney transplant recipients for the prophylaxis of CMV disease, with only slight excess in CNS adverse effects such as hallucination and confusion. ${ }^{80}$

Famciclovir was well tolerated in adult clinical trials for HSV and VZV infections. The most common adverse events were headache $(9.3 \%)$, nausea $(4.5 \%)$ and diarrhea $(2.4 \%){ }^{81}$ These reported adverse events were not serious and were comparable in incidence to the placebo group. No differences in adverse events were noted between acyclovir and famciclovir. Famciclovir is not recommended for use in pregnancy.

Compared to acyclovir, ganciclovir has similar activity against HSV and VZV. The enhanced anti-CMV activity is attributable to the lack of a hydroxyl group on the acyclic side chain. Nonetheless, this modification is associated with potentially serious side effects such as blood dyscrasias and fertility problems. Evidence from animal studies has shown ganciclovir to be teratogenic, mutagenic and carcinogenic. ${ }^{82}$ Contraceptive precautions for all patients may thus be required.

\section{Summary}

The rarity of ARN has hindered a development of RCTs in properly evaluating an ideal treatment protocol. The multipleviral etiology and need for PCR for proper identification can all contribute to potential delays in diagnosis, and the prescription of empirical treatment that has been based on past case reports. Advances in the use of novel agents have been limited to cases in which the causative virus is known to respond better to one agent (valganciclovir for CMV), or when conventional treatment has failed (famciclovir for acyclovir-resistant ARN). Safer methods to obtain intraocular samples for rapid viral identification, such as aqueous sampling rather than vitreous biopsy ${ }^{83}$ may allow prompt initiation of effective treatment.

Acyclovir and famciclovir, whether in the conventional intravenous or the oral-prodrug forms, have been proven to achieve therapeutic concentrations in the vitreous at conventional doses. The choice would then be decided on experience and safety profile. Acyclovir, and its newer analogue valacyclovir, remains the drug favored by most because of its efficacy and safety. Foscarnet and valganciclovir are usually recommended for retinitis in the immunocompromised, where CMV infection predominates. Intravenous and intravitreal ganciclovir has been used in case reports. ${ }^{84,85}$

What remains to be elucidated is the exact duration of treatment. Clinical examination has been the gold standard in monitoring treatment response and dosage titration. Newer methods, such as quantitative assays for viral DNA, may provide additional information and guide treatment in the future.

\section{Disclosures}

The authors report no conflicts of interest in this work.

\section{References}

1. Sternberg P, Knox DK, Finkelstein D, Green WR, Murphy RP, Patz A. Acute retinal necrosis syndrome. Retina. 1982;2:145-151.

2. Holland GN. Standard diagnostic criteria for the acute retinal necrosis syndrome. Executive Committee of the American Uveitis Society. Am J Ophthalmol. 1994;117:663-667.

3. Urayama A, Yamada N, Susaki T, et al. Unilateral acute uveitis with periarteritis and detachment. J Clin Ophthalmol. 1971;25: 607-619.

4. Culbertson WW, Blumenkranz, Haines H, Gass DM, Mitchell KB, Norton EW. The acute retinal necrosis syndrome. Part 2: Histopathology and etiology. Ophthalmology. 1982;89:1317-1325.

5. Culbertson WW, Blumenkranz MS, Popose JS, et al. Varicella zoster virus is a cause of the acute retinal necrosis syndrome. Ophthalmology. 1986;93:559-569.

6. Lewis ML, Culbertson WW, Post JD, et al. Herpes simplex virus type 1: a cause of the acute retinal necrosis syndrome. Ophthalmology. 1989; 96:875-878

7. de Boer JH, Luyendijk L, Rothova A, et al. Detection of intraocular antibody production to herpesviruses in acute retinal necrosis syndrome. Am J Ophthalmol. 1994;117:201-210.

8. Muthiah MN, Michaelides M, Child CS, Mitchell SM. Acute retinal necrosis: a national population-based study to assess the incidence, methods of diagnosis, treatment strategies and outcomes in the UK. Br J Ophthalmol. 2007;91:1452-1455. 
9. Sims JL, Yeoh J, Stawell RJ. Acute retinal necrosis: a case series with clinical features and treatment outcomes. Clin Experiment Ophthalmol. 2009;37:473-477.

10. Carney MD, Peyman GA, Goldberg MF, Packo J, Pulido J, Nicholson D. Acute retinal necrosis. Retina. 1986;6:85-94.

11. Hillenkamp J, Nolle B, Bruns C, Rautenberg P, Fickenscher H, Roider J. Acute retinal necrosis: clinical features, early vitrectomy, and outcomes. Ophthalmology. 2009;116:1971-1975.

12. Ishida T, Sugamoto Y, Sugita S, Mochizuki M. Prophylactic vitrectomy for acute retinal necrosis. Jpn J Ophthalmol. 2009;53:486-489.

13. Martenet A. "Necrose" retinienne peripherique et decollement retinien total d'origine vasculaire. 5th Congress Soc Europ Ophtal Hambourg, 1976. Enke, Stuttgart 1978;180-182.

14. Young NJA, Bird AC. Bilateral acute retinal necrosis. Br J Ophthalmol. 1978;62:581-590.

15. Blumenkranz MS, Culbertson WW, Clarkson JG, Dix R. Treatment of the acute retinal necrosis syndrome with intravenous acyclovir. Ophthalmology. 1986;93:296-300.

16. Crapotta JA, Freeman WR, Feldman RM, et al. Visual outcome in acute retinal necrosis. Retina. 1993;13:208-213.

17. Palay DA, Sternberg P, Davis J, et al. Decrease in the risk of bilateral acute retinal necrosis by acyclovir therapy. Am J Ophthalmol. 1991;112:250-255.

18. Kawaguchi T, Spencer DB, Mochizuki M. Therapy for acute retinal necrosis. Semin Ophthalmol. 2008;23:285-290.

19. Tran THC, Cassoux N, Bodaghi B, Lehoang P. Successful treatment with combination of systemic antiviral drugs and intravitreal ganciclovir injections in the management of severe necrotizing herpetic retinitis. Ocul Immunol Inflamm. 2003;11:141-144.

20. Kim SJ, Lo WR. Acute retinal necrosis. Ophthalmology. 2008;115: 1104-1105.

21. King J, Chung M, DiLoreto DA. A 9 year-old girl with herpes simplex virus type 2 acute retinal necrosis treated with intravitreal foscarnet. Ocul Immunol Inflamm. 2007;15:395-398.

22. Kim SJ, Equi R, Belair ML, Fine HF, Dunn JP. Long-term preservation of vision in progressive outer retinal necrosis treated with combination antiviral drugs and highly active antiretroviral therapy. Ocul Immunol Inflamm. 2007; 15:425-427.

23. Jabs DA, Schachat AP, Liss R, Knox DL, Michels RG. Presumed varicella zoster retinitis in immunocompromised patients. Retina. 1987;7:9-13.

24. Batisse D, Eliaszewicz M, Zazoun L, Baudrimont M, Pialoux G, Dupont B. Acute retinal necrosis in the course of AIDS: study of 26 cases. AIDS. 1996;10:55-60.

25. Chung H, Kim KH, Kim JG, Lee SY, Yoon YH. Retinal complications in patients with solid organ or bone marrow transplantations. Transplantation. 2007;83:694-699.

26. Torres JP, Concha EV, Juan P Lopez G, Jose Cofre G. Acute retinal necrosis in an acute leukemia pediatric patient. Rev Chilena Infectol. 2007;24:323-326.

27. Akpek EK, Kent C, Jakobiec F, Caliendo AM, Foster CS. Bilateral acute retinal necrosis caused by cytomegalovirus in an immunocompromised patient. Am J Ophthalmol. 1999;127:93-95.

28. Figueroa MS, Garabito I, Gutierrez C, Fortun J. Famciclovir for the treatment of acute retinal necrosis (ARN) syndrome. Am J Ophthalmol. 1997; 123:255-257.

29. Aslanides IM, De Souza S, Wong DTW, et al. Oral valacyclovir in the treatment of acute retinal necrosis syndrome. Retina. 2002;22:352-354.

30. Emerson GG, Smith JR, Wilson DJ, Rosenbaum JT, Flaxel CJ. Primary treatment of acute retinal necrosis with oral antiviral therapy. Ophthalmology. 2006;113:2259-2261.

31. Aizman A, Johnson MW, Elner SG. Treatment of acute retinal necrosis syndrome with oral antiviral medications. Ophthalmology. 2007; 114:307-312.

32. Elion GB, Furman PA, Fyfe JA, de Miranda P, Beauchamp L, Schaeffer HJ. Selectivity of action of an antiherpetic agent, 9-(2-hydroxyethoxymethyl) guanine. Proc Natl Acad Sci U S A. 1977;74:5716-5720.
33. Collins P. The spectrum of antiviral activities of acyclovir in vitro and in vivo. J Antimicrob Chemother. 12(Suppl B):19-27.

34. Biron KK, Elion GB. In vitro susceptibility of varicella-zoster virus to acyclovir. Antimicrob Agents Chemother. 1980;18:443-447.

35. Crumpacker CS, Schnipper LE, Zaia JA, et al. Growth inhibition by acycloguanosine of herpes viruses isolated from human infections. Antimicrob Agents Chemother. 1979;15:642-645.

36. De Miranda P, Blum MR. Pharmacokinetics of acyclovir after intravenous and oral administration. J Antimicrob Chemother. 12(Suppl B):29-37.

37. Sawyer MH, Webb DE, Balow JE, Straus SE. Acyclovir-induced renal failure. Clinical course and histology. Am J Med. 1988;84:1067-1071.

38. Keeney RE, Kirk LE, Bridgen D. Acyclovir tolerance in humans. Am J Med. 1982;73:176-181.

39. Schulman J, Peyman GA, Fiscella R, et al. Intraocular acyclovir levels after subconjunctival and topical administration. Br J Ophthalmol. 1986;70:138-140.

40. Schulman J, Peyman GA, Liu J, Scott M, Barber JC. The intraocular penetration of acyclovir after subconjunctival administration. Ophthalmic Surg. 1987;18:111-114.

41. Schulman JA, Peyman GA, Fiscella RG, Pulido J, Sugar J. Parentally administered acyclovir for viral retinitis associated with AIDS. Arch Ophthalmol. 1984;102:1750.

42. Hung SO, Patterson A, Rees PJ. Pharmacokinetics of oral acyclovir (Zovirax) in the eye. Br J Ophthalmol. 1984;68:192-195.

43. Englund JA, Zimmerman ME, Swierkosz EM, et al. Herpes simplex virus resistant to acyclovir: a study in the tertiary care center. Ann Intern Med. 1990;112:416-422.

44. Nugier F, Colin JN, Aymard M, Langlois M. Occurrence and characterization of acyclovir-resistant herpes simplex virus isolates: report on a 2-year sensitivity screening survey. K Med Virol. 1992;36:1-12.

45. Christophers J, Clayton K, Craske J, et al. Survey of resistance of herpes simplex virus to acyclovir in northewest England. Antimicrob Agents Chemother. 1998;42:868-872.

46. Larder BA, Cheng YC, Darby G. Characterization of abnormal thymidine kinases induced by drug-resistant strains of herpes simplex virus type 1. J Gen Virol. 1983;64:523-532.

47. Morfin F, Thouvenot D. Herpes simplex virus resistance to antiviral drugs. J Clin Virol. 2003;26:29-37.

48. Weller S, Blum MR, Doucette M, et al. Pharmacokinetics of the acyclovir pro-drug valaciclovir after escalating single- and multipledose administration to normal volunteers. Clin Pharmacol Therap. 1993;54:595-605.

49. Soul-Lawton J, Seaber E, On N, Wootton R, Rolan P, Posner J. Absolute bioavailability and metabolic disposition of valaciclovir, the L-valyl ester of acyclovir, following oral adminstration to humans. Antimicrob Agents Chemother. 1995;39:2759-2764.

50. Jacobson MA, Gallant J, Wang LH, et al. Phase 1 trial of valaciclovir, the L-valyl ester of acyclovir, in patients with advanced human immunodeficiency virus disease. Antimicrob Agents Chemother. 1994;38: 1534-1540

51. Wang LH, Schultz M, Weller S, Smiley ML, Blum MR. Pharmacokinetics and safety of multiple-dose valaciclovir in geriatric volunteers with and without concomitant diuretic therapy. Antimicrob Agents Chemother. 1996;40:80-85.

52. Perry CM, Faulds D. Valaciclovir: A review of its antiviral activity, pharmacokinetic properties and therapeutic efficacy in herpesvirus infections. Drugs. 1996;52:754.

53. Huynh TH, Johnson MW, Comer GM, Fish DN. Vitreous penetration of orally administered valacyclovir. Am J Ophthalmol. 2008; 145:682-686.

54. Lycke J, Malmestrom C, Stahle L. Acyclovir levels in serum and cerebrospinal fluid after oral administration of valacyclovir. Antimicrob Agents Chemother. 2003;47:2438-2441.

55. Vere Hodge RA, Cheng YC. Famciclovir and penciclovir. The mode of action of famciclovir including its conversion to penciclovir. Antiviral Chem Chemother. 1993;4:67-84. 
56. Thackray AM, Field HJ. Comparison of effects of famciclovir and valaciclovir on pathogenesis of herpes simplex virus type 2 in a murine infection model. Antimicrob Agents Chemother. 1996;40:846-851.

57. Thackray AM, Field HJ. Famciclovir and valaciclovir differ in the prevention of herpes simplex virus type 1 latency in mice: a quantitative study. Antimicrob Agents Chemother. 1998;42:1555-1562.

58. Perry CM, Wagstaff AJ. Famciclovir. A review of its pharmacological properties and therapeutic efficacy in herpesvirus infections. Drugs. 1995;50:396-415.

59. Chong DY, Johnson MW, Huynh TH, Hall EF, Comer GM, Fish DN Vireous penetration of orally administered famciclovir. Am JOphthalmol. 2009; 148:38-42.

60. Martin DF, Sierra-Madero J, Walmsley S, et al. A controlled trial of valganciclovir as induction therapy for cytomegalovirus retinitis. $N$ Engl J Med. 2002;346:1119-1126.

61. Savant V, Saeed T, Denniston A, Murray PI. Oral valganciclovir treatment of varicella zoster virus acute retinal necrosis. Eye. 2004; 18:544-555.

62. Cottet L, Kaiser L, Hirsch HH, Baglivo E. HSV2 acute retinal necrosis: diagnosis and monitoring with quantitative polymerase chain reaction. Int Ophthalmol. 2009;29:199-201.

63. Jung D, Dorr A. Single-dose pharmacokinetics of valganciclovir in HIV- and CMV-seropositive subjects. J Clin Pharmacol. 1999; 39:800-804.

64. Brown F, Banken L, Saywell K, Arum I. Pharmacokinetics of valganciclovir and ganciclovir following multiple oral dosages of valganciclovir in HIV- and CMV-seropositive volunteers. Clin Pharmacokinet. 1999;37:167.

65. Sawyer MH, Webb DE, Balow JE, Straus SE. Acyclovir-induced renal failure. Clinical course and histology. Am J Med. 1988; 84:1067-1071.

66. Tucker WE. Preclinical toxicology profile of acyclovir. Am J Med. 1982;73(Suppl):202-204.

67. Rashed A, Azadeh B, Abu Romeh SH. Acyclovir-indcued acute tubuleinterstitial nephritis. Nephron. 1990;56:436-438.

68. Eck P, Siler SM, Clark EC. Acute renal failure and coma after a high dose of oral acyclovir. N Engl J Med. 1991;325:182-185.

69. Keeney RE, Kirk LE, Bridgen D. Acyclovir tolerance in humans. Am J Med. 1982;73:176-181.

70. Izzedine H, Launay-Vacher V, Deray G. Antiviral drug-induced nephrotoxicity. Am J Kid Dis. 2005;45:804-817.

71. Davenport A, Goel S, Mackenzie JC. Neurotoxicity of acyclovir in patients with end-stage renal failure treated with continuous ambulatory peritoneal dialysis. Am J Kindey Dis. 1992;20:647-649.
72. Stone KM, Reiff-Eldridge R, White AD, et al. Pregnancy outcomes following systemic prenatal acyclovir exposure: Conclusions from the international acyclovir pregnancy registry, 1984-1999. Birth Defects Res Part A Clin Mol Teratol. 2004;70:201-207.

73. Vandercam T, Hintzen RQ, de Boer JH, Van der Lelij A. Herpetic encephalitis is a risk factor for acute retinal necrosis. Neurology. 2008;71:1268-1274.

74. Whitley RJ, Alford CA, Hirsch MS, et al. Vidarabine versus acyclovir therapy in herpes simplex encephalitis. $N$ Engl J Med. 1986;16;314: 144-149.

75. Valencia I, Miles DK, Melvin J, et al. Relapse of herpes encephalitis after acyclovir therapy: report of two new cases and review of the literature. Neuropediatrics. 2004;35:371-376.

76. Tyring S, Baker D, Snowden W. Valacyclovir for herpes simplex virus infection: long-term safety and sustained efficacy after 20 years' experience with acyclovir. J Infect Dis. 2002;186:S40-S46.

77. Bell WR, Chulay JD, Feinberg JE. Manifestations resembling thrombotic microangiopathy in patients with advanced human immunodeficiency virus (HIV) disease in a cytomegalovirus prophylaxis trial (ACTG 204). Medicine (Baltimore). 1997;76:369-380.

78. Hoglund M, Ljungman P, Weller S. Comparable acyclovir exposures produced by oral valaciclovir and itraveous acyclovir in immunocompromised cancer patients. J Antimicrob Chemother. 2001;47:855-861.

79. Alrabiah FA, Sacks SL. New antiherpesvirus agents: Their targets and therapeutic agents. Their targets and therapeutic potential. Drugs. 1996;52:17-32.

80. Lowance D, Neumayer HH, Legendre CM, et al. Valacyclovir for the prevention of cytomegalovirus disease after renal transplantation. International Valacyclovir Cytomegalovirus Prophylaxis Transplantation Study Group. N Engl J Med. 1999;340:1462-1470.

81. Saltzman R, Jurewicz R, Boon R. Safety of famciclovir in patients with herpes zoster and genital herpes. Antimicrob Agents Chemother. 1994;38:2454-2457.

82. Abdel-Haq N, Chearskul P, Al-Tatari H, Asmar B. New antiviral agents Indian J Pediatr. 2006;73:313-321.

83. Rothova A, de Boer JH, Ten NJ, et al. Usefulness of aqueous humor analysis for the diagnosis of posterior uveitis. Ophthalmology. 2008;115:306-311.

84. Tran THC, Stanescu D, Caspers-Velu L, et al. Clinical characteristics of acute HSV-2 retinal necrosis. Am J Ophthalmol. 2004; 137:872-879.

85. Tajunisah I, Reddy SC, Tan LH. Acute retinal necrosis by cytomegalovirus in an immunocompetent adult: case report and review of the literature. Int Ophthalmol. 2009;29:85-90. 


\section{Appendix I}

Summary of the different antivirals used in acute retinal necrosis (ARN)

\begin{tabular}{|c|c|c|c|c|c|}
\hline & Acyclovir & Valacyclovir & Famciclovir & Foscarnet & Valganciclovir \\
\hline Dose & $\begin{array}{l}\text { iv } 10-13 \mathrm{mg} / \mathrm{kg} 3 \text { times } \\
\text { daily for } 5-10 \text { days, then } \\
400-800 \mathrm{mg} 5 \text { times } \\
\text { daily for } 6-8 \text { weeks po }\end{array}$ & $\begin{array}{l}\text { I-2 g } 3 \text { times daily } \\
\text { for } 6-8 \text { weeks }\end{array}$ & $\begin{array}{l}500 \text { mg } 3 \text { times daily po } \\
\text { for } 12 \text { weeks, followed } \\
\text { by taper for } 13 \text { weeks }\end{array}$ & $\begin{array}{l}2.4 \mathrm{mg} / 0 . \mathrm{l} \mathrm{mL} \\
\text { intravitreal as initial } \\
\text { treatment }\end{array}$ & $\begin{array}{l}\text { I g } 3 \text { times daily po } \\
900 \text { mg twice daily } \\
3 \text { weeks induction, then } \\
900 \mathrm{mg} \text { daily for } 2 \text { weeks } \\
\text { before switching to oral } \\
\text { acyclovir }\end{array}$ \\
\hline Use & Current standard & $\begin{array}{l}\text { Emerging standard } \\
\text { because of comparable } \\
\text { AUC but lower peak } \\
\text { concentrations, which } \\
\text { translates to safer profile }\end{array}$ & Acyclovir resistance & $\begin{array}{l}\text { Systemic treatment } \\
\text { contraindicated, one } \\
\text { case of childhood } \\
\text { HSV-2 ARN }\end{array}$ & $\begin{array}{l}\text { As substitute to } \\
\text { existing regimen }\end{array}$ \\
\hline Adverse effects & $\begin{array}{l}\text { CNS toxicity: lethargy, } \\
\text { delirium, seizures, renal } \\
\text { failure }\end{array}$ & $\begin{array}{l}\text { Hemolytic uremic } \\
\text { syndrome, thrombotic } \\
\text { thromboycytopenic } \\
\text { purpura (in } \\
\text { immunocompromised } \\
\text { patients }>8 \mathrm{~g} / \text { day) }\end{array}$ & $\begin{array}{l}\text { Minimal Similar } \\
\text { to placebo }\end{array}$ & $\begin{array}{l}\text { Nil reported when } \\
\text { given intravitreally }\end{array}$ & $\begin{array}{l}\text { Myelotoxicity, sterility, } \\
\text { CNS abnormalities }\end{array}$ \\
\hline
\end{tabular}

Abbreviations: AUC, area under the concentration-time curve CNS, central nervous system; HSV, herpes simplex virus; PO, by mouth; IV, intravenous.

Clinical Ophthalmology

\section{Publish your work in this journal}

Clinical Ophthalmology is an international, peer-reviewed journal covering all subspecialties within ophthalmology. Key topics include: Optometry; Visual science; Pharmacology and drug therapy in eye diseases; Basic Sciences; Primary and Secondary eye care; Patient Safety and Quality of Care Improvements. This journal is indexed on

Submit your manuscript here: http://www.dovepress.com/clinical-ophthalmology-journal

\section{Dovepress}

PubMed Central and CAS, and is the official journal of The Society of Clinical Ophthalmology (SCO). The manuscript management system is completely online and includes a very quick and fair peer-review system, which is all easy to use. Visit http://www.dovepress.com/ testimonials.php to read real quotes from published authors. 